\title{
THE FORMATION OF TRANSLATORS' RESEARCH COMPETENCE AT THE UNIVERSITIES OF UKRAINE
}

\author{
Marianna Knyazyan ${ }^{1}$, Natalia Mushynska ${ }^{2}$ \\ ${ }^{1}$ Odessa National University named after I.I. Mechnikov, Ukraine \\ E-Mail: kniazian1970@gmail.com \\ ${ }^{2}$ Odessa Institute of Trade and Economics of Kyiv National University of Trade and Economics, Ukraine \\ E-Mail: ameline@ukr.net
}

\begin{abstract}
This study explores the essence and the structure of the translators' research competence, as well as the development of the system for its formation. We have developed a system of 12 interrelated segments of the research skills of translator: the development of the initial research base, the study of theoretical information, data collection (translation), data collection (didactics), data processing, pedagogical model of the experimental forming stage, argumentation of personal position, generalization of experimental data, forecasting the research prospects, presenting the research results, publication of research results, selfesteem. In accordance with the scientific positions, we offered to evaluate the level of formation of research skills in accordance with the criterion of the performance accuracy of skills presented in each segment. The obtained data revealed low, medium, and high levels of formation of research skills. We have evaluated the level of students' knowledge about the main categories of research activity. In order to form the research competence of translators, we have developed the tasks aimed at the formation of research skills, knowledge about the organization of research activities in the field of translation studies.
\end{abstract}

Key words: translator's research competence, research methods, research skills, interrelated segments of skills, task, data collection

\section{INTRODUCTION}

In the context of increasing globalization, priority is given to the formation of research competence of translators, which allows training of the students for independent knowledge expansion in the field of theoretical and applied linguistics, forms such analytical, prognostic, reflexive, communicative skills that allow effective organizing of research and literature studying activities, research organization, results approbation.

It should be noted that at the universities of Ukraine, in particular at the Odessa National University named after I.I. Mechnikov, Izmail State University of Humanities, masters of the specialty "Philology" receive professional qualifications not only of translators, but also of lecturers for higher education system, which increases their competitiveness, provides great opportunities for employment. We emphasize that in this case it becomes necessary to harmonize the features of the didactic and translational components of the program of their professional training, to ensure a high level of their professionalism avoiding excessive academic overburden of students. 
It is obvious that the formation of research competence becomes a priority due to the fact that a modern translator, as well as a lecturer, has to deal with rapidly accumulating and changing information, taking into account many contexts (sociocultural, historical, professional, educational, personal). In addition, a translator and a lecturer must constantly improve themselves, deepening their individual lexical vocabulary, familiarizing themselves with literary works, scientific texts, and journalism. It is important to expand their erudition, the knowledge acquisition about various spheres of society, the mastery of modern information and communication technologies. Analysis of the literature suggests that scientists considered the competence approach (Bardière, 2016; Kaskatayeva, 2014; Lamblin et al, 2010; Ruchen, 2003; Shubina et al, 2014), and the activity approach (Khromchenko, 2014; Knyazian, 2018) as the methodological basis for solving these problems, covered the methods of formation of research competence and its individual components of future teachers (Šeberová, 2008; Kastakaeva, 2014; Yarullin et al, 2015), and of schoolchildren (Martel, 2018; Willison et al, 2012). The problem of skills development through research is also the focus of scientists (Kalugina, 2015; Saldanha et al, 2014; Vaillant, 2015). Thiel F., Böttcher F. (2014) studied the model of interdisciplinary research competence, which includes research, methodical, communicative, reflexive competences, as well as knowledge. At the same time, the problem of the formation of research competence of future translators requires further study.

\section{METHODS}

The aim of the article is to disclose the essence and the structure of the research competence of translators and lecturers, as well as the development of the system for its formation. It determines the following measures: the study of programmes and teaching and methodological materials to support the translators' professional training; self-assessment and expert assessment of the results of the students' research activities.

Diagnosis of the formation of research competence was carried out using a technique that involves testing. The test consisted of certain blocks in accordance with the components of the research competence of the students. Each of these blocks contained both a test with variants of answers, which made it possible to diagnose students' theoretical knowledge, as well as tasks of a problematic nature. Theoretical methods were used to solve the research problems: systematic theoretical analysis and generalization of the results of psychological, pedagogical research, study of instructions and regulatory documentation and educational and methodological support for the professional training of masters of professional qualification "translator, lecturers of foreign languages and literature"; systematization, comparison and generalization to determine the conceptual apparatus of research, to ground the pedagogical means for the formation of the translators' research competency. Empirical research methods: pedagogical experiment with the aim of the formation of the research competence; quantitative and qualitative analysis of the obtained results using the methods of mathematical statistics.

\section{DOCUMENTATION ANALYSIS}

Documentation analysis, which provides information about the qualification, suggests that the obtained qualification is master degree, program subject area 'Philology', 
Germanic / Romance languages and literatures (including translation), lecture of the Eglish (French / Spanish / German) and French (Eglish / Spanish / German) languages and literatures at college and universities, translator. Concerning the level of qualification, the documents indicate that the second level (master's) of higher education corresponds to eighth level of the National Qualification Framework and provides for the ability of a person to solve complex problems and tasks in the area of their professional activity or during the programme course which implies research and innovation amid ambiguous conditions and requirements.

The knowledge and understanding envisage such as fundamental knowledge of philology: modern languages and world literature teaching methodology in schools, colleges, higher education institutions of I-IV accreditation levels; master conceptions in Humanities, Education, and Social Sciences. The students have profound knowledge of Ukrainian and two modern languages; they obtain knowledge of structure of the third modern language. It is especially emphasized that the students use Humanities and Social Sciences methodology in research work and teaching; know how to use modern scientific methods of philological research, be trained in carrying out research in philology.

Speaking about the application of knowledge and understanding, the students must speak two modern languages and be able to use them in oral and written communication in different professional areas, interpret / translate and edit business communication and texts of different genres and styles. It is necessary to pay attention to the fact that the students must conduct independent research into modern languages, implement methods of linguistic and literary analysis and scientific achievements in modern linguistics. Besides that, they know technology of learning and teaching modern languages and world literature, understand the essence of educator's professional culture, and master the basis of pedagogical proficiency and educational methodology.

Analyzing the educational components of the professional training of translators and teachers at the Odessa National University by I.I. Mechnikov, one should pay attention to the fact that they can be systematized in these three main areas: linguistic (for example, "Linguistic Theory", "Gender Linguistics", "Modern Cognitive Studies and Organization of Research", "Modern Grammar Trends"), translational ("Theory and Practice of Translation", "Country Studies and Translation"), and didactic ("University Pedagogies", "Literature and Language Teaching Methodology in Higher Education Institutions", "Intercultural aspects of learning English / German / French / Spanish").

It is the formation of research competence on the basis of the above-mentioned linguistic and didactic disciplines that helps ensure the effective formation of skills such as express their own view clearly, consistently, and reasonably using background and professional knowledge.

\section{RESEARCH RESULTS}

The formation of research competence of masters of professional qualification "translator, lecturer of foreign languages and literature" at the Odessa National University named after I.I. Mechnikov, was carried out at such stages: theoretical (analysis of scientific resources, the definition of the concepts "translators' research competence", "lecturers' research competence", characterization of the components of these types of competence), empirical (data collection), didactic (forming experiment). 


\subsection{Theoretical background}

Competence is determined by the experts of the programme DeSeCo as the ability to respond to individual and social needs successfully, to complete set tasks. At the same time, competence is based on a combination of mutually relevant cognitive relationships, practical skills, emotions, and knowledge, that is, everything that can be mobilized for activity (2002: 8).

In addition, The APEC / Deloitte Consulting study conducted a study of the skills that a researcher should have today and by 2020 (2010: 6). The researcher should expand the range of their skills in addition to the skills in his scientific field. Thus, according to the authors, the researcher must have 20 key competences, among which there are three such groups: scientific competencies; project and team management skills; personal aptitudes / interpersonal skills.

Some of the above mentioned skills are also part of the interdisciplinary research competence model, which was developed by F. Thiel, F. Böttcher (2014: 116). This model displays, in general, the logical sequence of research in the context of any academic discipline, the scientific sphere. In particular, the authors distinguish four groups of skills: skills of analyzing the level of the research; among the methodological skills the authors include the definition and practical realization of research hypotheses, planning the research process, the selection and implementation of adequate methods. A special place is occupied by the comprehension of the results of research activities: for example, students must take into account the implementation of the results of their research, its methodological restrictions, practical and ethical consequences. Not less important in the structure of research competence are communication skills, in particular, the writing of a scientific publication, the presentation of research results.

In the scientific literature, the problems of formation of the research competence of teachers are studied. For example, A. Šeberová (2008) defines this competence as an open and developing system of declarative and procedural knowledge in the field of research, a positive attitude towards it, which allows teachers to organize research as part of their own educational practice in the field of education.

J. Willison, K. O'Regan (2012) distinguished such 6 groups of criteria for assessing the level of development of research skills. Among these research skills the following are mentioned: embark and clarify, find and generate, evaluate and reflect, organise and manage, analyse and synthesise, communicate and apply.

Taking into account the above mentioned approaches, we will consider research competence as the ability for cognitive activity, possession of professionally significant knowledge, as well as the ability to study phenomena in the context of their systemic interconnection at the empirical and theoretical levels with the aim to expand both the scientific foundation and their own experience.

The research competence of a translator reflects interests in the subject and process of research activity, complex of research activities, including the development of the initial research base, the study of theoretical information, its critical evaluation, conducting of empirical research, the system of processing and synthesis of received experimental data, the development of theoretical constructs of the phenomenon under study (concepts, models, classifications, etc.), argumentation of one's own scientific position, the forecast of prospective in the study of the problem under consideration, presentation of the results of scientific research, reflection. 
The specificity of the research competence of lecturers lies in the fact that it involves the generation of extraordinary ideas in the field of education, the development and argumentation of their own methods of teaching and educational impact on students, increasing the effectiveness of their professional training, analyzing and designing the necessary theoretical generalizations, and expanding of acquired knowledge in a wide professional context, the activation of their own self-development.

We have developed a system of 12 interrelated segments of the research skills of translator and lecturer. Those skills that are specific to the translation or didactic sphere have been distinguished: RST (research skills of translator), RSL (research skills of lecturer), as well as skills that are common (they were designated RSTL (research skills of translator and lecturer)).

1) Development of the initial research base (RSTL): the formation of a transdisciplinary research plan; a vision of various aspects of the problem in theory and practice; defining the problem in such a way that it contains an indication of the final goal, conditions and restrictions of the study; differentiating the main and minor problems; justification of the object of research. The definition of the research objective provides for its variability, differentiation. The development of a hypothesis is aimed at the generation of extraordinary, original, interesting ideas, their differentiation and synthesis, possibility of nomination of several hypotheses, their mobile analysis and reconstruction; rejection of previously defined unproductive hypotheses. This complex also includes such projective actions as the creation of a plan-prospect of research work, effective time management, selection and combination of research methods, their variation; switching from one method to another; creating a new combination of known methods; evaluation and justification of the practicability of the chosen research methods; search for several programmes of development of the research phenomena. Among the research skills of this segment, such important ones as the generation of new ideas and hypotheses should be mentioned, which lay the core of the research around which the scientific reasoning and approbation of the research results is built. It is this segment of research skills that provides the flexibility, completeness and logical planning and programming of the research, the coherence of the sequence of tasks.

2) Study of theoretical information (RSTL): work with bibliography and archive; complete set of own catalog of scientific works, their reference and informational reading. The analysis of scientific and theoretical sources on the studied problem is carried out. In the aspect of didactics, students also study normative, instructive-methodical, as well as educational documentation (various types of records of both teachers and students). This segment of research study also includes the selection of necessary information, its annotation, making abstracts, writing resume, selection of quotations. In addition to the study of scientific and theoretical sources, the student organizes interviews with competent persons.

3) Data collection (RST): comparative analysis, collection and documentation of translation units at phonetic, morphemic, morphological, syntactic, semantic, stylistic levels, translational transformations, identification of levels of translation equivalence to the original, analysis of types of adaptive transcoding.

4) Data collection (RSL): conducting observation, communication, interviewing, questioning, testing, expert review, ranking, sociometric analysis.

5) Data processing (RSTL): selection and multidimensional analysis of the material, comparison of separate elements of the phenomenon under study, combination, classification, systematization of empirical data, their grouping, new synthesis of the elements of phenomena, mathematical and statistical verification of research results. 
6) Model development in the forming stage of the pedagogical experiment (RSL): finding contradictions in concepts, theories, statements, identifying the dependence between the facts of pedagogical reality, a comprehensive, multidimensional analysis of the links between them; creation of a conceptual model of the functioning of a pedagogical phenomenon; development of experimental pedagogical technology and strategies for its implementation in the educational process; the use of analogies; playback of several solutions to the problem, dynamic change of search directions. The system of pedagogical means is developed which is directed for the increasing the efficiency of the educational process in solving a specific problem. The principles and conditions for the implementation of the forming experiment are revealed; possible results are predicted.

7) Argumentation of personal position (RSTL): proof of own position, which involves the selection of arguments, facts, quotations in support of personal ideas.

8) Generalization of experimental data (RSTL): the crystallization of the final decision, when the situation is seen from a new point of view; the characteristic of new, previously unknown quality; comparing the results of the experiment with the theory; generalization of research results; formulating conclusions; assessment of correspondence of the received results with the goals and conditions of the task.

9) Forecasting the research prospects (RSTL): identifying prospects for conclusions and generalizations, anticipating the consequences of the study, predicting possible options for the development of the phenomena under study.

10) Presenting the research results (RSTL): presenting a scientific text with full justification of the concept of the author and the received materials in accordance with modern requirements. When presenting a scientific text, the special significance acquires the expression of personal research position in accordance with the requirements of correctness, expressiveness, clearness, accuracy, conciseness and practicability. These factors ensure the optimal presentation of the scientific material by student, and achievement of understanding of the scientific position by readers or listeners.

11) Publication of research results (RSTL): presenting of scientific reports at conferences of various levels, publication of research results in the form of proceedings, articles in paper and electronic media.

12) Self-esteem (RSTL): analysis of the effectiveness of research activities, the degree of realization of the goal, completeness of the tasks fulfillment; identification of deficiencies, generalization of positive and negative experience.

We would like to mention that there is dialectic interdependence between the designated segments: the processes of goal setting, the definition of a hypothesis, the development of a research programme and the development of its methodology provide for the implementation of predictive appraisal of their possible effectiveness. The generalization of activities orients the student to a constant correlation of the received data with plan, objectives, and research hypothesis. There is a systemic interpenetration and interdependence of the above mentioned research skills.

\subsection{Empirical stage of formation of research competence of translators, lecturers of foreign languages and literature}

In the course of an empirical study of the problem of the formation of the competence under consideration, the students of the Faculty of Romance and Germanic Philology of the Odessa National University by I.I. Mechnikov were asked to evaluate the level of their research skills in each of the segments of the translator's and teacher's system. 


\subsubsection{Data collection}

It should be mentioned that J. Willison, K. O'Regan (2012) suggested 5 levels of research skills depending on the student autonomy in the process of doing research: level 1 (prescribed research), level 2 (bounded research), level 3 (scaffolded research), level 4 (student-initiated research), level 5 (open research).

In accordance with the scientific position of N. Kalugina, H. Gireva, Yu. Kalugin, I. Varlamova, we offered to evaluate the level of formation of research skills in accordance with the criterion of the performance accuracy of skills presented in each segment using the following formula:

$$
k_{a}=\frac{n}{N},
$$

where $k_{a}$ - the coefficient of the action, $n$ - the number of actions that were performed correctly; $N$ - is the total number of actions that need to be performed in a certain segment (2015: 1).

The obtained data revealed low, medium, high levels of formation of research skills. We support the scientific position of $N$. Kalugina, H. Gireva, who offered while calculating the results to give 0 points to a low level of formation of research skills, 1 point to the medium level, 2 points to the high level (Table 1).

Table 1 Levels of formation of research skills

\begin{tabular}{|l|c|c|}
\hline $\begin{array}{l}\text { Levels of } \\
\text { Formation of } \\
\text { Research Skills }\end{array}$ & $\begin{array}{l}\text { The Number of Actions } \\
\text { that were performed } \\
\text { correctly in Tasks (in \%) }\end{array}$ & Points \\
\hline High & $75 \% \leq n \leq 100 \%$ & 2 \\
\hline Medium & $50 \% \leq n<75 \%$ & 1 \\
\hline Low & $33 \% \leq n<50 \%$ & 0 \\
\hline
\end{tabular}

Total of 70 students from intramural and extramural four departments (of English, German, French, Spanish philology) of the Faculty of Romance and Germanic Philology of the Odessa National University by I.I. Mechnikov took part in the testing. On the basis of the received results we calculated the arithmetic average for each segment of the system of research skills of the students. The received data indicates that students, in general, have formed research skills of all segments, but the highest result was received in the aspect of studying theoretical information $(1,64)$ and collecting data in the field of didactic studies $(1,63)$. It should be noted that the lowest result was received in the aspect of model development in the forming stage of the pedagogical experiment $(1,17)$, which is explained by a more active involvement of students in the context of linguistic research (Table 2).

In addition, the volume of linguistic disciplines in the professional training of teachers, translators occupies the biggest part in the total volume of academic disciplines. 
Table 2 Segments of the system of the students' research skills

\begin{tabular}{|c|l|c|c|c|}
\hline Segment & Research Skills & RSTL & RST & RSL \\
\hline 1) & The development of the initial research base & 1,36 & - & - \\
\hline 2) & The study of theoretical information & 1,64 & - & - \\
\hline 3$)$ & Data collection (RST) & - & 1,52 & - \\
\hline 4$)$ & Data collection (RSL) & - & - & 1,63 \\
\hline 5$)$ & Data processing & 1,53 & - & - \\
\hline 6$)$ & $\begin{array}{l}\text { Model development in the forming stage of the } \\
\text { pedagogical experiment }\end{array}$ & - & - & 1,17 \\
\hline 7$)$ & Argumentation of personal position & 1,49 & - & - \\
\hline 8$)$ & Generalization of experimental data & 1,52 & - & - \\
\hline 9$)$ & Forecasting the research prospects & 1,45 & - & - \\
\hline 10$)$ & Presenting the research results & 1,48 & - & - \\
\hline 11$)$ & Publication of research results & 1,44 & - & - \\
\hline 12$)$ & Self-esteem & 1,56 & - & - \\
\hline
\end{tabular}

For the same reason, when estimating the motivation for research, we have revealed the students' dominating interest for the research in the field of linguistics, in particular, translation studies. For example, in the questionnaire process there was the question "Which academic subject out of ten offered in the list is the most interesting for you as a basis for conducting research activities?" (Rate the degree of interest on a scale from 1 ("causes minimum interest") to 10 ("causes maximum interest") the students primarily named such as "Country Studies and Translation", "Theory and Practice of Translation", "Modern Cognitive Studies and Organization of Research", "Linguosynergetics", "Psycholinguistics".

\subsubsection{Forming experiment}

With the aim of formation of the translators' research competence, we have developed and suggested tasks directed for the gradual formation of research studies, knowledge about the peculiarities of organization of research activity in the field of translation studies, as well as didactics.

Below we present the ranking of tasks; we should note that, depending on the field in which the tasks were applied (translation or didactics), their content also changed: analysiscommentary of basic scientific concepts, development of the initial base of research, individual or collective expert review, projecting of optimal means for the research procedures, task 'prospective research', task 'creative precedent', organization of student scientific conference.

For example, the analysis-commentary of basic scientific concepts suggested that masters should designate a scientific concept (this is an object, phenomenon, process, type of activity, ability or quality of a person, etc.), determine its attributive characteristics, analyze basic functions, and make a comment regarding the field of scientific usage. The development of the initial base of the research was aimed for the defining of the purpose, subject, object, hypothesis, research objectives, analysis of the system of methods, disclosure of the fields of their implementation. The individual expert review suggested the selection, reinterpretation and generalization of theoretical information representing different scientific points of view on the solution of a particular problem. The creative 
precedent suggested carrying out the brainstorming (students analyzed the literature on a specific issue, showed deficiency and perspectives of the concept, generated their personal versions, selected the best options, and proved their effectiveness).

\section{CONCLUSION}

This study analyzed the essence and the structure of the research competence of translators and lecturers. At the universities of Ukraine, in particular at the Odessa National University named after I.I. Mechnikov, masters of the specialty "Philology" receive professional qualifications not only of translators, but also of lecturers for higher educational system. The difference between the research competence of a translator and a teacher of higher education has been analyzed. We have developed a system of 12 interrelated segments of the research skills of translator. We also evaluated the level of students' knowledge about the main categories of research activity, in particular about the essence of research methods, technologies and tools for conducting scientific research in translation studies.

In order to form the research competence of translators, we have developed the tasks aimed at the formation of research skills, knowledge about the organization of research activities in the field of translation studies, as well as didactics.

\section{REFERENCES}

Bardière, Yv. 2016. "De la pragmatique à la compétence pragmatique". Recherches en didactique des langues et des cultures [En ligne], 13-1 | 2016, mis en ligne le 25 juillet 2016, consulté le 07 février 2017. URL : http://rdlc.revues.org/462 ; DOI : $10.4000 /$ rdlc. 462

Definition and Selection of Competencies. Theoretical and Conceptual Foundations (DESECO). Strategy Paper on Key Competencies. An Overarching Frame of Reference for an Assessment and Research Program - OECD (Draft). 2002. http:// www.kaapeli.fi/ $\sim$ vsy/eaea/policy/b/DeSeCo.doc.

Kalugina, N., Gireva, H., Kalugin, Yu., Varlamova, I. 2015. "Criteria of Formation of Students' Research Skills of Technical Universities”. Successes of Modern Natural Science. No 7: 98-101. http://www.natural-sciences.ru/ru/article/view?

Kaskatayeva, B. 2014. "Pedagogical conditions for forming the research competency in future teachers of mathematics". Rural Environment. Education. Personality. No. 7-8: 103-109.

Khromchenko, E. 2014. "Pedagogical Conditions of Preparation of Future Teachers of Philological Specialties to Organize Educationsl and Research Activity of Senior Pupils". The Second International conference on development of pedagogical science in Eurasia, Vienna: 41-45.

Kniazian, M. 2018. "The Methods to form the Future Teachers' Analytical and Interpretative Writing (in Universities of Izmail and Odessa)". Journal of Danubian Studies and Research. Vol 8 No 2: 310-320.

Lamblin, P., Etienne C., Meunier M.-C., Bancal M., Lenot O., Davo J. Skills and competencies needed in the research field objectives 2020. APEC; DELOITTE, 2010.

Lipatov, S. A. 2005. "Organizational diagnostics: theoretical and methodological grounds”. Personality. Culture Society. Vol VII No 3 (27): 153-172. 
Malinovski, B. A Scientific Theory of Culture. Chapell Hill: The University of North Carolina Press, 2004.

Martel, V. 2018. "Développer des compétences de recherche et de littératie au primaire et au secondaire: former à l'enquête en classe d'histoire". Les Éditions JFD. https://books.google.com.ua/books?id=_jFtDwAAQBAJ\&pg

Research Competencies Framework. The Royal College of Surgeons of England, 2007. https://www.rcpch.ac.uk/sites/default/files/2018-04/rcseng__consultant_surgeon_and_consultant_delivered_service.pdf

Ruchen, D. S. Key Competencies for a Successful Life and a Well-Functionin Society. Hogrefe \& Huber Publishers, Germany, 2003.

Saldanha, G., O’Brien, S. Research Methodologies in Translation Studies. Routledge.Taylor \& Francis Group, London and New York, 2014.

Šeberová, A. 2008. "La compétence de recherche et son développement auprès des étudiants - futurs enseignants en République tchèque". Recherche et formation. 59: 59-74.

Shubina, I., Zavrazhin, A. 2014. "Competence approach to education: from theory to practice". Australian Journal of Scientific Research. 2(6): 164-170.

Yarullin I., F., Bushmeleva, N. A., Tsyrkun I. I. 2015. "The Research Competence Development of Students Trained In Mathematical Direction". Mathematics Education. 10(3): 137-146.

Willison, J., O’Regan K. 2012. "Research Skill Development (RSD), a conceptual framework for Primary school to PhD". Framework, resources, learning modules and references. http://www.rsd.edu.au.

Vaillant, J. 2015. "Du projet de la profession au développement des compétences par la recherche”. Kinésithérapie. Vol 15, No 167: 52-55. 